\title{
The fatty acids based organofunctional silane protective coatings for concrete
}

\author{
ํㅣ. Szubert \\ Faculty of Chemistry, Adam Mickiewicz University in Poznan, (Poznan, Poland) \\ * karolszu@amu.edu.pl
}

Received: 25 March 2020

Accepted: 05 August 2020 Available on line: 10 March 2021

\begin{abstract}
The possibility of using free fatty acids for the synthesis of new organofunctional silanes is shown. In nature, fatty acids occur in the form of esters with glycerin (fats) and are widely used for production of soap, oil paints, medicines and cosmetics. Of particular interest in this study was the application of organosilicon derivatives of oleic acid for production of coating that would cover the surface of concrete and protect it from water permeation. As a result of proposed silanization, the concrete surface acquired hydrophobic character with the wetting angles up to $115^{\circ}$, and the concrete absorbability was reduced by up to $93 \%$.
\end{abstract}

KEYWORDS: Fatty acids; Sol-gel processes; Organically modified silanes; Concrete; Protective coatings.

Citation/Citar como: Szubert, K. (2021) The fatty acids based organofunctional silane protective coatings for concrete. Mater. Construcc. 71 [341], e238 https://doi.org/10.3989/mc.2021.03420

RESUMEN: Revestimientos protectores de silano organofuncional a base de ácidos grasos para el hormigón. Se muestra la posibilidad de usar ácidos grasos libres para la síntesis de nuevos silanos organofuncionales. En la naturaleza, los ácidos grasos se encuentran en forma de ésteres con glicerina (grasas) y son ampliamente usados para la fabricación de jabones, pinturas de aceite, medicamentos y productos cosméticos. En este estudio fue de particular interés la aplicación de derivados organosilíceos del ácido oleico para la producción de un revestimiento que cubriera la superficie del hormigón y lo protegiera de la permeación del agua. Como resultado de la silanización propuesta, la superficie del hormigón adquirió carácter hidrofóbico con los ángulos de mojado hasta $115^{\circ}$, y su capacidad de absorción se redujo hasta en un $93 \%$.

PALABRAS ClAVE: Ácidos grasos; Procesos sol-gel; Silanos modificados orgánicamente; Hormigón; Revestimientos protectores.

Copyright: (C2021 CSIC. This is an open-access article distributed under the terms of the Creative Commons Attribution 4.0 International (CC BY 4.0) License. 


\section{INTRODUCTION}

A reinforced concrete is a strong and hard material used for construction but it can undergo corrosion as a result of water permeation inside the concrete structures. As together with water many aggressive substances get inside the concrete structures, the surface absorbability of concrete is an important factor determining the stability of concrete constructions (1-4). One of the effective methods of concrete protection from the adverse effects of water is covering its surface with a protecting coat restricting the permeation of aggressive agents.

A silicon-based compounds, such as silanes, siloxanes and silicones have been often applied in building industry (5). Organofunctional alkoxysilanes are monomeric silicon compounds that as a result of hydrolysis and condensation produce a stable polysiloxane coating that covers the pore surface. According to literature (6) silanes enter the concrete pores and react with their surface changing its character into more hydrophobic and inhibit permeation of water and ions solved in water. In sol-gel procces the silane undergoes hydrolysis, the alkoxy groups are hydrolyzed with generation of silanol groups. Then, the unstable silanol molecules lose water and undergo condensation making silicon resin. Moreover, some silanol groups from the silicon resin react with hydroxyl groups in the concrete substrate through hydrogen bonds. Finally, silicon resin binds to the substrate in the process of drying and endows the hydrophobic properties to the surface. The concrete alkalinity acts as a catalyst in this reaction (7). The hydrolysis and condensation reactions take place simultaneously, and the coating obtained as a result of the sol-gel process has a complicated, spatially expanded structure. A simplified scheme of the concrete surface silanization in the sol-gel process is presented below (Figure 1).

The obtained coating is well bonded to the substrate by creating a chemical bond between the siloxane and the hydroxyl groups of the mineral substrate. The hydrophobic character of this coating comes from alkyl groups (8-11). The coating restricts the water permeation but allows water vapour transfer towards outside of a given concrete element (12). According to literature reports, the application of silanes significantly reduces the amount of water that permeates the concrete structure, which also limits the permeation of chlorides and reduces the risk of corrosion of concrete reinforcement elements (13). It should also be emphasized that silane treatment can not only provide a hydrophobic surface, but also make the substrate surface tougher prevent cracking and heal cracks smaller than $0.2 \mathrm{~mm}$ (14). A summary on the effect of silane-based impregnating agents on corrosion of concrete was provided by Pan et al. $(6,15)$.

Dai et al. (16) used silane/siloxane based systems to impregnate the concrete surface. A $35-45 \%$ solutions of triethoxyoctylsilane in isopropanol was used, the silane was used in the amount of $115 \mathrm{~g} / \mathrm{m}^{2}$ when the concrete surface was covered three times by spilling the solution onto the concrete surface. This treatment significantly reduced the capillary water absorption of the treated concrete by more than $90 \%$, but without the complete impermeability of the concrete. Similar results were obtained by Zhan et al. (17), the impregnation of the concrete surface with pure triethoxyoctylsilane by immersing the samples in silane. With a silane consumption of $600 \mathrm{~g} / \mathrm{m}^{2}$ a reduction in water absorption of over $90 \%$ was obtained. Christodoulou et al. (13) presented the effects of silane impregnation 20 years after the treatment. Concrete cores were taken from reinforced concrete bridges and their water absorption was compared with untreated control cores. The results showed that a $20 \%$ aqueous solution of alkyltrialkoxysilane can provide protection against water. According to the presented results, the "fresh" silane impregnated samples (after 1 month) showed a reduction in absorption by at least $90 \%$, after 12 years it was $78 \%$, and after $18-70 \%$. The silane solution was applied by brush painting in the silane amount of $600-1000 \mathrm{~g} / \mathrm{m}^{2}$. Another approach applied in order to restrict the adverse effect of water on concrete is the addition of hydrophobic admixtures at the stage of its production (18). The hydrophobic agents

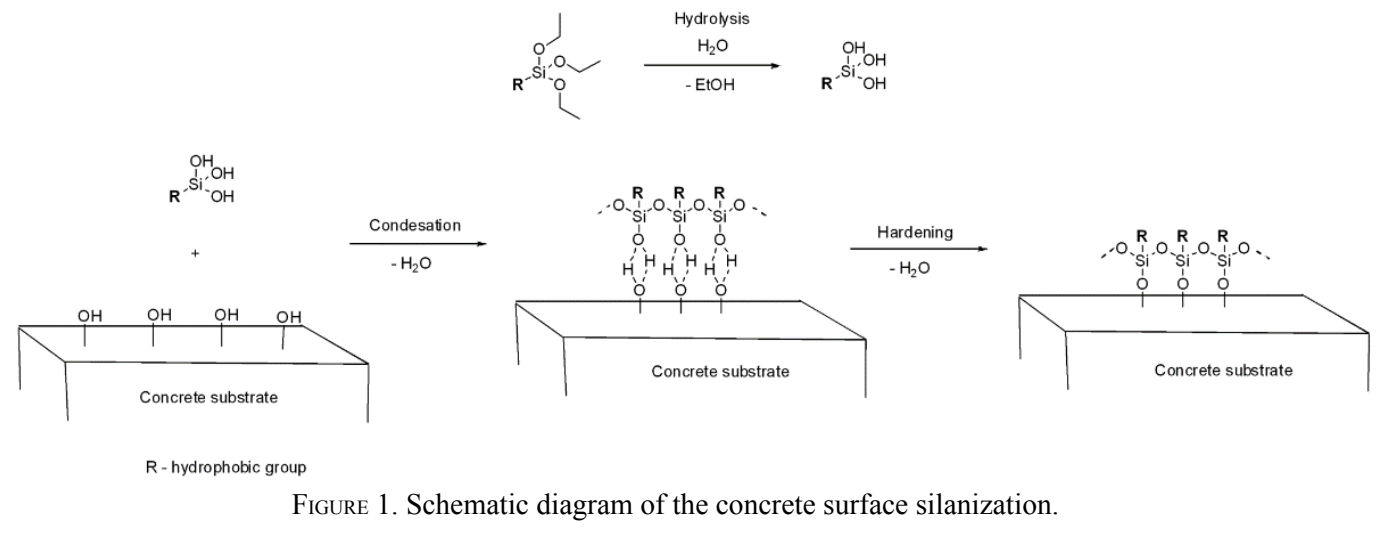


such as fatty acids, their salts (soap), vegetable oils, wax emulsions and animal fats, were commonly used concrete additives in ancient Rome. Ancient treatises (e.g. Vitruvius, Pliny) mention the use of linseed oil as an additive or as a protective treatment for mortars and other building materials to improve hydrophobicity. Malinowski (19) studied the Caesarea Roman aqueduct and states that some type of oil was added as recommended by Vitruvius. A recent study enabled the detection of linseed oil in the mortar beneath the mosaics of the vaults of Saint Peter's Basilica that was also cited in ancient recipes related to the construction of the basilica (20). The fatty acids derivatives as a hydrophonic agents change the surface tension in pores and cracks, which limits water permeation $(18,21,22)$. The chemical structure and properties of fatty acids make them suitable for addition to concrete. Long-chain fatty acids derivatives (oils, soaps) can be added to concrete, where they precipitate as insoluble calcium salts. This deposit gives a hydrophobic coating to the capillary surface, and also blocks some pores in fresh concrete. The pore system that develops during the later hydration steps ( $>24$ hours) is not affected by this sediment, hence the saturated permeability is not reduced. (23). The carboxyl group can be attracted to the positively charged colloid particles in concrete in a way similar to attraction of carboxyl group in polycarboxylate ether (PCE) which is a popular superplasticizer (24). Moreover, liquid fatty acids have sufficiently high surface tension $\left(2-310^{-4} \mathrm{~N} / \mathrm{m}\right)$ to be retained in composite material (25). Some admixtures tend to entrain air, leading to a permanent reduction in strength conversion (23). Due to the reduced movement of moisture in the concrete containing these admixtures, moisture and efflorescence can be eliminated. This group of materials will restrict the flow of water through the dry concrete which would normally occur by capillary action rather than by external water pressure. In general, all these materials are believed to give the concrete surface hydrophobic properties and can block the pores. The detailed mechanism is unclear, but it has been suggested that the hydrophobic effect is related to the electrostatic charge transferred to the capillary walls. Justnes et al. (26) tested a number of vegetable oils as hydrophobic agents in mortars. They were dispersed in water and added to the cement. Vegetable oils hydrolyzed ii the present of hydroxides in pore water. Cheap canola oil seemed to be most effective.

Our earlier papers present the synthesis of alkoxysilyl derivative based on rapeseed oil by the reaction of nucleophilic substitution of 3-chloropropyltrimethoxysilane with appropriate sodium salts (rapeseed soap) (27). The obtained silane has been used for production of wood (27) and steel (28) surface coa- ting protecting from the adverse effect of water. The silane obtained according to the latter procedure was dark in color as a consequence of iodine compounds presence; potassium iodide was used as a catalysts of the nucleophilic substitution reaction. The almost black color of the silane is undesirable for its potential applications in formation of protective coatings as the final color of the protected surface would be changed. That is why alternative methods for silane synthesis have been searched for.

In this paper we report on an alternative method of synthesis of the above-mentioned silane from the commercially available oleic acid (OPTES - (oleatepropyl)triethoxysilane) and propose its use for making concrete surface coating protecting from water permeation inside its structure. The silane obtained by hydrosilylation of allyl oleate shows light yellow color, which has no undesirable effect on the color of the protected surface. No intensive color change of the reaction mixture indicates no side reactions chemical decomposition of the compound). Possible side reaction products were removed while purification, additionally NMR analysis showed no presence of decomposition products.

\section{MATERIALS AND METHODS}

\subsection{Materials}

The used reagents were purchased from SigmaAldrich and used without further purification. Concrete samples were made of Portland concrete type 32.5 (GÓRAŻDŻE CEMENT S.A., Poland) consistent with EN 197-1 (29), gravel with a maximum grain size of $16 \mathrm{~mm}$ and sand with a maximum grain size of $4 \mathrm{~mm}$ (Kruszgeo, Poland). Water for concrete preparation was taken from water supply system.

\subsection{Synthesis of Oleic acid based silane OPTES}

In the experiment we used OPTES silane obtained from the commercially available oleic acid of natural origin (natural, Sigma-Aldrich). Oleic acid belongs to monounsaturated fatty acids, it is present in large amounts in vegetable oils, e.g. olive oil and rapeseed oil (30). The synthesis of OPTES runs in two stages. At first oleic acid is subjected to esterification reaction with allyl alcohol to give allyl oleate, which is then subjected to hydrosilylation with triethoxysilane to give the desired OPTES. The OPTES structure is shown below (Figure 2).

\subsubsection{Synthesis of Allyl Oleate}

Concentrated sulfuric acid $(1 \mathrm{~mL})$ was added on vigorous stirring to a solution of oleic acid (30 g, 
$0.1 \mathrm{~mol})$ in allyl alcohol $(100 \mathrm{~mL})$ and stirred under reflux overnight. After this time, the mixture was evaporated under reduced pressure and diethyl ether $(100 \mathrm{~mL})$ was added to the crude product. Then the mixture was washed thrice with brine $(3 \times 75 \mathrm{~mL})$. Separation was difficult when the organic layer was washed with water, a stable suspension was formed. Separation was easier with brine added. Additionally, wash with brine allows to remove large amounts of water than may be dissolved in the organic layer. The allyl oleate solution in ether was dried with magnesium sulfate overnight, filtered and diethyl ether was evaporated under reduced pressure (29.7 g, yield: $92 \%$ ).

\subsubsection{Synthesis of the OPTES silane via hydrosilylation reaction}

The platinum Karstedt catalyst $\left(9 \times 10^{-7}\right.$ mol of $\left.\mathrm{Pt}\right)$ was added to the mixture of allyl oleate from the previous step $(29.7 \mathrm{~g}, 0.09 \mathrm{~mol})$ with triethoxysilane $(17.85 \mathrm{~g}, 0.11 \mathrm{~mol})$ followed by heating to $80{ }^{\circ} \mathrm{C}$ for over $1 \mathrm{~h}$. After the reaction mixture was cooled down, the excess of triethoxysilane was evaporated under vacuum to give the product as a yellow liquid (43.5 g, yield 99\%). Results of NMR analysis of the product confirmed its structure and purity:

${ }^{1} \mathrm{H}$ NMR $\left(\mathrm{C}_{6} \mathrm{D}_{6}, 298 \mathrm{~K}, 500 \mathrm{MHz}\right) \delta=0.64(\mathrm{t}$, $\left.2 \mathrm{H}, \mathrm{SiCH}_{2}-\right) ; 0.87\left(\mathrm{t}, 3 \mathrm{H},-\mathrm{CH}_{3}\right) ; 1.22(\mathrm{t}, 9 \mathrm{H}, \mathrm{Si}-$ $\left.\mathrm{O}-\mathrm{CH}_{2}-\mathrm{CH}_{3}\right) ; 1.26-1.30\left(\mathrm{~m}, 20 \mathrm{H},-\mathrm{CH}_{2}^{-}\right) ; 1.61$ $\left(\mathrm{m}, 2 \mathrm{H}, \mathrm{Si}-\mathrm{CH}_{2}-\mathrm{CH}_{2}-\right) ; 1.73\left(\mathrm{~m}, 2 \mathrm{H}, \mathrm{C}(\mathrm{O})-\mathrm{CH}_{2}-\right.$ $\left.\mathrm{CH}_{2}-\right) ; 2.00\left(\mathrm{~m}, 4 \mathrm{H},-\mathrm{CH}_{2}-\mathrm{CH}=\right) ; 2.28(\mathrm{t}, 2 \mathrm{H}$, $\left.\mathrm{C}(\mathrm{O})-\mathrm{CH}_{2}-\right) ; 3.81\left(\mathrm{q}, 6 \mathrm{H}, \mathrm{Si}-\mathrm{O}-\mathrm{CH}_{2}-\mathrm{CH}_{3}\right) ; 4.03$ $\left(\mathrm{t}, 2 \mathrm{H},-\mathrm{CH}_{2}-\mathrm{O}-\mathrm{C}(\mathrm{O})-\right)$; $5.33(\mathrm{~m}, 2 \mathrm{H},-\mathrm{CH}=\mathrm{CH}-)$ ppm.

${ }^{13} \mathrm{C} \quad \mathrm{NMR}\left(\mathrm{C}_{6} \mathrm{D}_{6}, 298 \mathrm{~K}, 126 \mathrm{MHz}\right) \delta=$ $6.53\left(\mathrm{SiCH}_{2}-\right) ; 14.06\left(-\mathrm{CH}_{3}\right) ; 18,26\left(\mathrm{Si}-\mathrm{O}-\mathrm{CH}_{2}-\right.$ $\left.\mathrm{CH}_{3}\right)$; 22.23-34.31 (-CH$\left.{ }_{2}^{-}\right) ; 58.36\left(\mathrm{Si}-\mathrm{O}-\mathrm{CH}_{2}-\right.$ $\left.\mathrm{CH}_{3}\right) ; 66.24$ (- $\left.\mathrm{CH}_{2}-\mathrm{O}-\mathrm{C}(\mathrm{O})-\right) ; 129.68,129.91$ ($\mathrm{CH}=\mathrm{CH}-) ; 173.77(\mathrm{C}=\mathrm{O}) \mathrm{ppm}$.

${ }^{29} \mathrm{Si} \mathrm{NMR}\left(\mathrm{C}_{6} \mathrm{D}_{6}, 298 \mathrm{~K}, 99 \mathrm{MHz}\right) \delta=$ $-45.89 \mathrm{ppm}$.

\subsection{Concrete preparation procedure}

The concrete samples were made of a mixture containing $1295 \mathrm{~kg} / \mathrm{m}^{3}$ of coarse aggregate (gravel),
$595 \mathrm{~kg} / \mathrm{m}^{3}$ of fine aggregate (sand), $380 \mathrm{~kg} / \mathrm{m}^{3}$ of cement and $190 \mathrm{~kg} / \mathrm{m}^{3}$ of water. The ratio of free water to cement (w/c) was set to 0.5 . Fresh concrete was poured out and subjected to vibrations in the form of cube of the size 100x100x100 mm. The cubic samples were demolded after $24 \mathrm{~h}$ of curing, then they were placed in a curing room $\left(20 \pm 2{ }^{\circ} \mathrm{C}\right.$, relative humidity $(\mathrm{RH}) \geq 90 \%$ ) for 28 days.

\subsection{Preparation of hydrophobic coating}

The hardened samples of concrete were washed in water to remove all loose parts and dried for 5 days, then the samples were subjected to silanization. Solutions of OPTES in ethanol were prepared. The first solution (O1) was obtained by adding $25 \mathrm{~g}$ of OPTES, $5 \mathrm{~g}$ of water and $5 \mathrm{~g}$ of concentrated hydrochloric acid to $465 \mathrm{~g}$ of ethanol. The second solution (O2) contained $25 \mathrm{~g}$ of OPTES, $25 \mathrm{~g}$ of tetraethoxysilane (TEOS), $5 \mathrm{~g}$ of water, $5 \mathrm{~g}$ of concentrated hydrochloric and $440 \mathrm{~g}$ of ethanol. Next, the solutions were stirred for 3 hours (O1.3 and $\mathrm{O} 2.3$ ) or 72 hours (O1.72 and $\mathrm{O} 2.72)$. After the indicated time the samples were used for concrete surface silanization. Deposition was carried out in two ways. In the first, concrete were immersed in the solutions for 1 hour. After taking out from the solution, the samples were dried at room temperature for 24 hours. In the second, the solutions were applied using a brush on the surfaces of concrete samples and repeated after 2 hours. Finally, the concrete samples were dried at room temperature for 24 hours also.

The consumption of the silane solution was calculated from the weight loss of the OPTES solution $(\mathrm{g})$ by the silanized surface area $\left(\mathrm{m}^{2}\right)$.

\subsection{Analyses and measurements}

The NMR analyses $\left({ }^{1} \mathrm{H},{ }^{13} \mathrm{C}\right.$ and $\left.{ }^{29} \mathrm{Si} \mathrm{NMR}\right)$ were carried out using a Bruker Avance III $500 \mathrm{MHz}$ spectrometer, samples for analysis were prepared in chloroform-d $\left(\mathrm{CDCl}_{3}\right)$.

Scanning electron microscopy (SEM) images were taken on a FEI Quanta 250 FEG microscope working in high vacuum mode with $10 \mathrm{kV}$ accelerating voltage. EDS Octane SDD detector (EDAX) with electron beam energy of $20 \mathrm{keV}$ was used for EDS mapping. The smaller concrete cubes $(10 \times 10 \times 10 \mathrm{~mm})$ were cut from the samples described in 2.3 and used to take the SEM images.

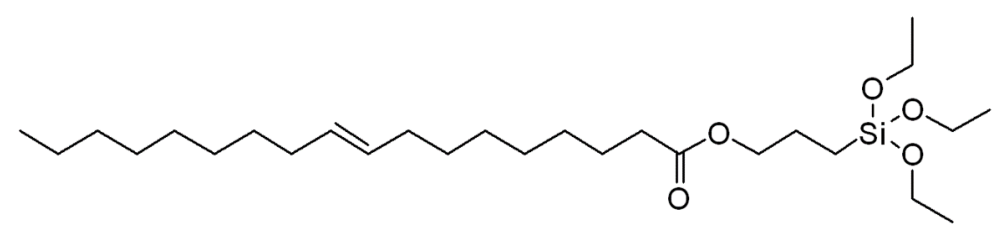

OPTES

FigurE 2. The OPTES structure. 
The Drop Shape Analyzer Krüss DSA 100 were used for static water contact angle (WCA) measurements. The analyzer was equipped with a softwarecontrolled (DAS4 2.0): x, y, z-axis table, quadruple dosing unit and a camera with $780 \times 580$ px resolution. A $5 \mu 1$ volume of water droplet was applied for WCA measurement. The obtained WCA values are arithmetic averages of measurements made for 5 drops per sample. The measurements of WCA were performed $30 \mathrm{~s}$ after the deposition of a drop on a studied surface. In an additional experiment on the surface of the concrete sample a drop of water containing a dye was placed in order to observe the hydrophobic character of the surface, the drop containing $0.1 \%$ solution of methyl orange had a volume of $20 \mu 1$.

The liquid water permeability test was applied for determination of the concrete cubes absorbability of water through capillary suction, according to the norm EN 1062-3 (31). The samples were weighed prior to submerging in water and after $24 \mathrm{~h}$ in water. The water level on the tray was at $5-10 \mathrm{~mm}$ above the bottom of the concrete sample. The liquid water permeability after $24 \mathrm{~h}(\mathrm{w})$ was calculated using Equation [1], where $\Delta \mathrm{m}_{24}$ is mass variation before and after $24 \mathrm{~h}$ of submerging $(\mathrm{kg})$ in water and $\mathrm{A}$ is the surface area of the sample $\left(\mathrm{m}^{2}\right)$ :

$$
w=\frac{\Delta m_{24}}{\sqrt{24 \times A}}\left[\mathrm{~kg} /\left(\mathrm{m}^{2} \times \mathrm{h}^{0.5}\right]\right.
$$

The silanization solution penetration depth was determined according to the norm EN-1504-2 (32). In order to determine the depth of the silanization solution penetration into the concrete sample, after silanization the concrete cubes were fractured in two parts. Then the fracture surface was sprayed with water, the border between the bright area (the silanized region not wetted by the water) and the dark area (the region wetted by the water) marks the depth of penetration of the silanization solution into the concrete.

\section{RESULTS AND DISCUSSION}

As mentioned in the experimental part, prior to silanization of the concrete surface with the solutions the latter were stirred for 3 and 72 hours. The time of stirring was chosen on the basis of earlier experiments on silanization of steel and wood surfaces. The OPTES enter the concrete pores and react with their surface according to sol-gel mechanism, $\mathrm{Ca} / \mathrm{Si}-\mathrm{O}-\mathrm{Si}$ bonds are formed. From the chemical point of view OPTES (see Figure 2) is an ester of a higher fatty acid and on the concrete surface may also decompose to form calcium oleate, similar to described the use of butyl stearate as an additive in concrete (23). This compound was used in fresh concrete and reacts slowly to form a water-insoluble calcium stearate. In the case of silanization the concrete surface, the impact of this process should be infinitesimal.

Two methods of protective coatings application were used in the research: by immersing concrete samples in a silane solution and by painting the concrete surface twice with a brush. The immersion method is often used in academic research, but in practice it cannot be used for silanizing the surfaces of large concrete objects. Additionally, both of the applied methods of coating application are characterized by a similar consumption of OPTES. The average consumption of the OPTES in the immersion method was $20.9 \pm 1.0 \mathrm{~g} / \mathrm{m}^{2}\left(418 \pm 20 \mathrm{~g} / \mathrm{m}^{2}\right.$ calculated for the OPTES solutions), while in the case of painting the concrete surface twice with a brush, it was $22.9 \pm 1.4 \mathrm{~g} / \mathrm{m}^{2}\left(458 \pm 28 \mathrm{~g} / \mathrm{m}^{2}\right.$ calculated for the OPTES solutions).

Figure 3 presents exemplary SEM images of the concrete before and after silanization. The concrete surface before silanization was rough but uniform. After silanization (sample O1.3) an additional layer covering the porous concrete surface is seen. Comparison of Figure $3 \mathrm{a}$ and $3 \mathrm{c}$ shows that silanization did not lead to complete filling of the concrete pores. The photos taken at 200x magnification show open pores, both in the case of the unmodified concrete surface (Figure 3a) and in the case of silanized surfaces (Figure 3c). The attached SEM images confirm that OPTES behaves like a typical hydrophobic impregnation agent $(6,32)$. Figure $3 \mathrm{~d}$ taken at a greater magnification $(10 \mathrm{kx})$, shows characteristic crackings and fissures, typical of the silica structures obtained by the sol-gel method (27), in the layer covering the concrete surface.

Figure 4 presents exemplary EDS mapping of carbon, silicon and calcium atoms present on the concrete surface. The light regions correspond to the sites with carbon, silicon and calcium atoms, while the dark regions correspond to the areas without these atoms. The images of unmodified concrete reveal the dominant presence of silicon and calcium in the concrete mixture. Additionally, silicon atoms dominate in areas with a deficit of calcium atoms. After silanization, EDS images show much greater content of carbon, which comes from OPTES, it can be seen that the regions with carbon atoms correspond with regions containing silicon atoms. Also the content of silicon is greater in the sample modified with silane in the contrast to unmodified concrete. Comparing the EDS mapping of silicon and calcium atoms on the concrete surface after silanization, can be noticed that these atoms also appear in the same regions (see mapping of silicon and calcium on the surface of unmodified concrete), which indicates that the calcium-rich areas are also covered with the siloxane layer. 


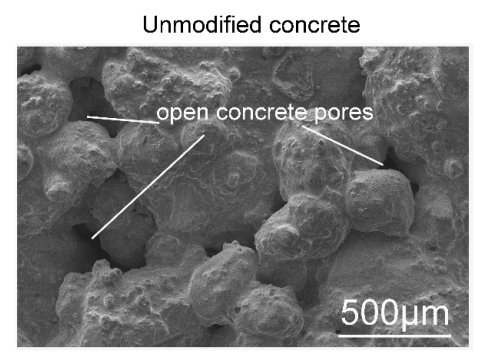

(a) $200 x$

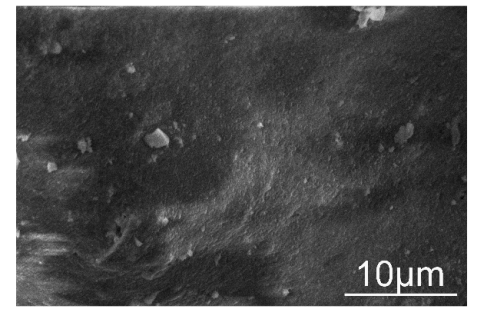

(c) $10 \mathrm{kx}$

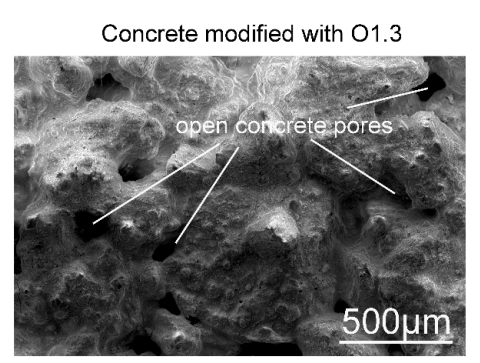

(b) $200 x$

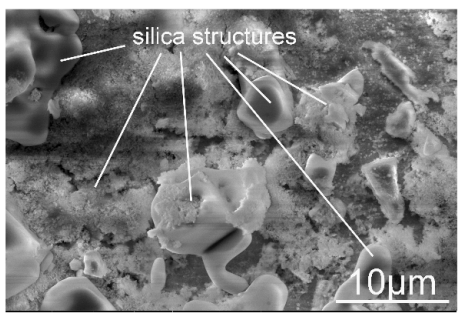

(d) $10 \mathrm{kx}$

Figure 3. SEM image of the unmodified concrete (a, c) and concrete with the modified surface, sample O1.3 (b, d).

Usually to increase the concrete hydrophobic character the use of concentrated silane solutions and higher silan consumption is needed $(5,16,17)$, for OPTES it was sufficient to use 5\% alcohol silane solutions. The WCA measurements are collected in Table 1.

TABLE 1. Water contact angle (WCA) values of concrete without and with OPTES treatment.

\begin{tabular}{cc}
\hline Sample & WCA/degree \\
\hline concrete & - \\
\hline \multicolumn{3}{c}{ Immersion } \\
\hline $\mathrm{O} 1.3$ & $114.6 \pm 4.52$ \\
$\mathrm{O} 1.72$ & $113.5 \pm 5.94$ \\
$\mathrm{O} 2.3$ & $112.1 \pm 5.07$ \\
$\mathrm{O} 2.72$ & $112.1 \pm 5.27$ \\
\hline $\mathrm{O} 1.3$ & \\
$\mathrm{O} 1.72$ & $104.8 \pm 5.77$ \\
$\mathrm{O} 2.3$ & $113.6 \pm 1.53$ \\
$\mathrm{O} 2.72$ & $101.4 \pm 7.41$ \\
\hline
\end{tabular}

Correct measurement of the contact angle on the surface of unmodified concrete was impossible because the water droplet was immediately spilled and absorbed into the sample, which confirmed high water absorbability and strongly hydrophilic character of concrete. The contact angles measured for the concrete surface modified with alcohol solutions of OPTES were above $101^{\circ}$, which confirms the hydrophobic character of the modified surfaces. Moreover, it should be emphasized that the contact angles were measured at 30 seconds after placing water droplet on the surface and during this time the water droplet did not change shape (did not spill out) and its volume did not decrease (water was not absorbed). For all modified concrete samples the average contact angles were similar. The slightly lower values of the angles were obtained for the concrete surface modified by brush painting, however, these values are still within the standard deviations. Figure 5 presents the water droplets dyed with methyl orange deposited on the unmodified and silanized concrete surface, immediately after droplet deposition and after its evaporation. As mentioned earlier, the water droplet deposited on the unmodified concrete surface immediately spills over a relatively large irregular area and disappears (gets absorbed), Figure 5a. While a drop of water placed on the surface of the concrete after silanization maintains its regular shape with a small contact area between the drop and the concrete surface (Figure 5b). After complete evaporation of the water, on the surface of unmodified concrete (Figure 5c), an irregularly shaped dye remained, the surface of the concrete coated with the dye is smaller than the area immediately after the drop of water with methyl orange, which indicates a strong water capillary rise. Whereas, a regular circular stain of dye remained on the concrete surface after the droplet was evaporated (Figure 5d). The behavior of water drops on the surface of unmodified and silanized concrete were as expected and consistent with the previous results of contact angles measurements. It should be emphasized that all modified concrete samples behaved in a similar way. 


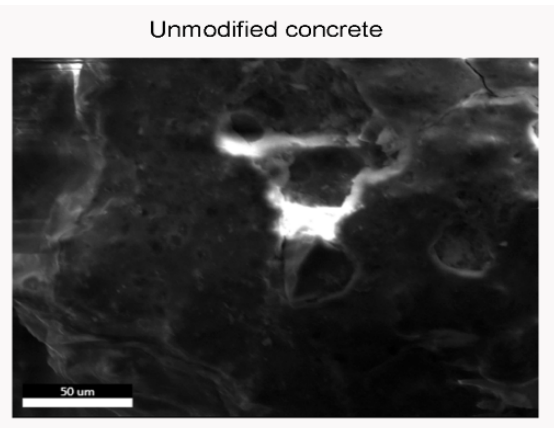

(a) Back-scattered electron image

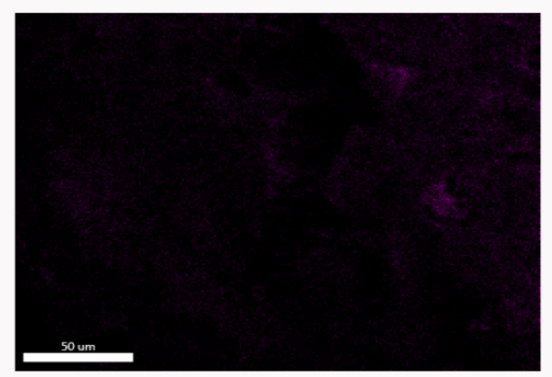

(c) Element map of $\mathrm{C}$

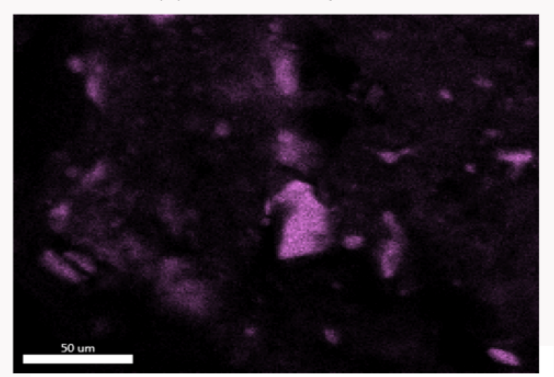

(e) Element map of $\mathrm{Si}$

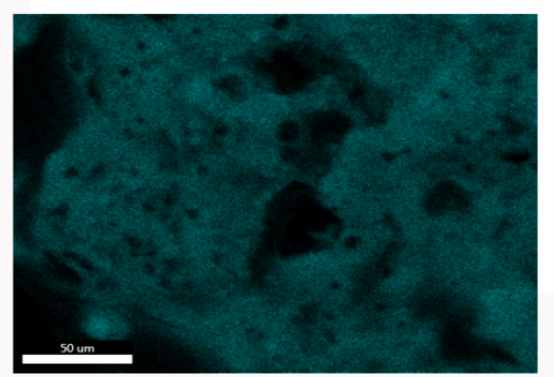

(g) Element map of $\mathrm{Ca}$

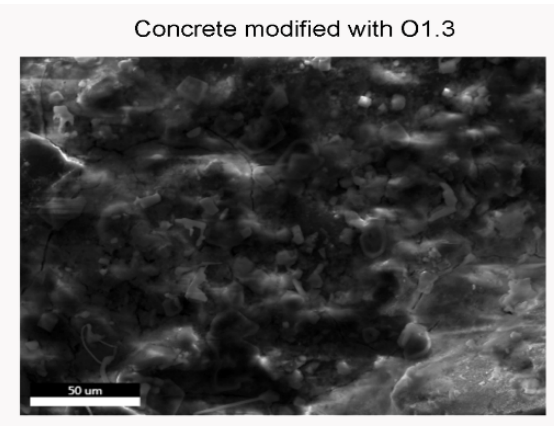

(b) Back-scattered electron image

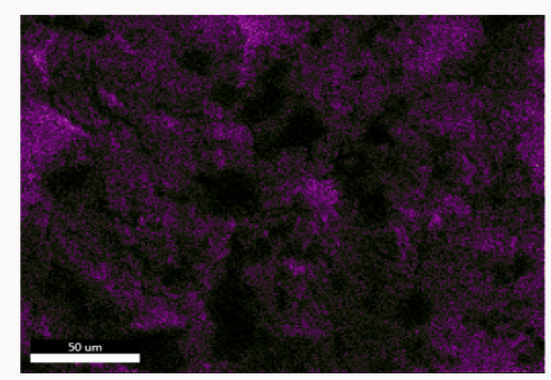

(d) Element map of $\mathrm{C}$

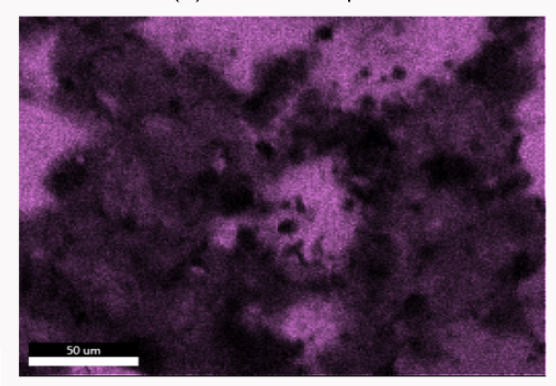

(f) Element map of $\mathrm{Si}$

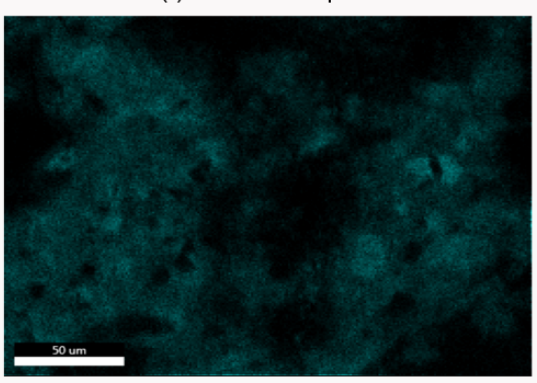

(h) Element map of $\mathrm{Ca}$

FIGURE 4. EDS mapping of the elements occurring on the surface of unmodified concrete (a, c, e, g) and silanized sample O1.3 (b, d, f, h).

As mentioned above, the absorbability measurements were performed according to EN-1062-3 (31). The water absorbability (w) data are summarized in Table 2.

The result obtained for the unmodified concrete was similar to that obtained by Baltazar et. al. (33), while the water absorbability coefficients obtained for the samples subjected to silanization are indicative of a significant restriction of water transport into the inner structure of concrete. For samples $\mathrm{O} 1.3$ and $\mathrm{O} 1.72$ subjected to impregnation by immersion with solutions containing OPTES, the wa- ter absorbability was reduced by $92.7 \%$ and $89.5 \%$, respectively. Longer time of stirring of the solution with OPTES slightly reduced the barrier effect of the coating produced. For samples O2.3 and O2.72 coated with the material containing an addition of TEOS, the water absorbability was reduced by about $93 \%$, the effect of extended time of stirring was also insignificant and could be neglected. According to the results the coatings obtained from the solutions containing an addition of TEOS show a little better barrier properties. For these coatings a longer time of stirring of the relevant solutions had less effect on 
the results obtained. In the case of coatings obtained as a result of brush painting, similar water absorbability were obtained. An improvement in barrier properties can be noticed in the case of samples mixed for 3 hours, for both tested solutions, a reduction in water absorbability by $95 \%$ was achieved. When the solutions mixed for 72 hours were used, the results were slightly worse compared to those obtained by immersion. Analyzing the obtained results, it can also be noticed that the addition of TEOS has a beneficial effect on the barrier properties of coatings obtained from solutions with longer mixing time.

TABLE 2. Water permeability (w) after $24 \mathrm{~h}$ of immersion of concrete samples without and with OPTES treatment.

\begin{tabular}{|c|c|c|}
\hline Sample & $\mathbf{w}\left[\mathbf{k g} / \mathbf{m}^{2} \mathbf{h}^{0,5}\right]$ & $\begin{array}{c}\text { Relative impro- } \\
\text { vement in ab- } \\
\text { sorbability [\%] }\end{array}$ \\
\hline concrete & $0.4777 \pm 0.0420$ & - \\
\hline \multicolumn{3}{|c|}{ Immersion $\left(20.9 \pm 1.0 \mathrm{~g} / \mathrm{m}^{2}\right)$} \\
\hline O1.3 & $0.0347 \pm 0.0012$ & 92.7 \\
\hline $\mathrm{O} 1.72$ & $0.0503 \pm 0.0046$ & 89.5 \\
\hline $\mathrm{O} 2.3$ & $0.0323 \pm 0.0025$ & 93.3 \\
\hline $\mathrm{O} 2.72$ & $0.0363 \pm 0.0012$ & 92.5 \\
\hline \multicolumn{3}{|c|}{ Brush painting $\left(22.9 \pm 1.4 \mathrm{~g} / \mathrm{m}^{2}\right)$} \\
\hline O1.3 & $0.0253 \pm 0.0021$ & 94.8 \\
\hline $\mathrm{O} 1.72$ & $0.0617 \pm 0.0040$ & 87.0 \\
\hline $\mathrm{O} 2.3$ & $0.0240 \pm 0.0017$ & 95.0 \\
\hline $\mathrm{O} 2.72$ & $0.0423 \pm 0.0020$ & 91.2 \\
\hline
\end{tabular}

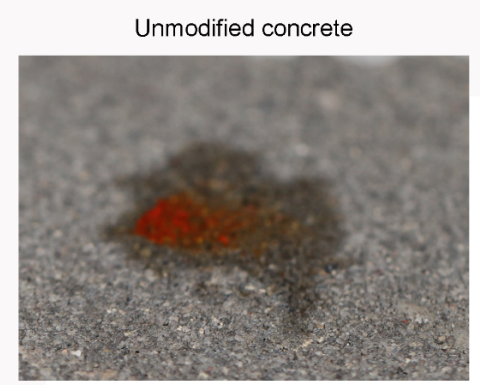

(a) water droplet directly after deposition

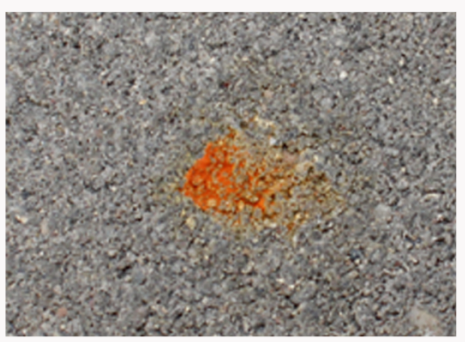

(c) water droplet after evaporation
The depth of silanes penetration into concrete was measured according to EN-1504-2 (32). The cubes of concrete were cut and the surfaces of the break were sprayed with water. Figure 6 shows examples of the wet cutting surface, the surface coated with silane was not wetted and was much brighter than the deeper layers of the concrete sample which were well wetted with water. In all samples of modified by immersion concrete, the silanizing solutions penetrated to the depth of 4-5 mm, while in the case of surfaces painted with a brush, silane penetrated to a a lower depth (3-4 mm).

\section{CONCLUSIONS}

The silane obtained as a result of hydrosilylation of allyl oleate shows only slight coloring which has no effect on the color of the material coated, in contrast to almost black silane obtained according to the earlier proposed method of its synthesis. It is especially important considering the potential application of this type of hydrophobic impregnation for the protection of decorative building materials, such as architectural concrete, bricks or stones. The use of OPTES silane reduced the water absorbability of modified concrete by up to $95 \%$. It should be emphasized that a good barrier effect was achieved at low silane concentrations, several times lower than previously described in the literature. It has been shown that extended time of stirring the solutions containing TEOS prior to their application for silanization of concrete surface has insignificant effect on the parameters of the coatings obtained. It seems that the addition of TEOS stabilizes the solutions

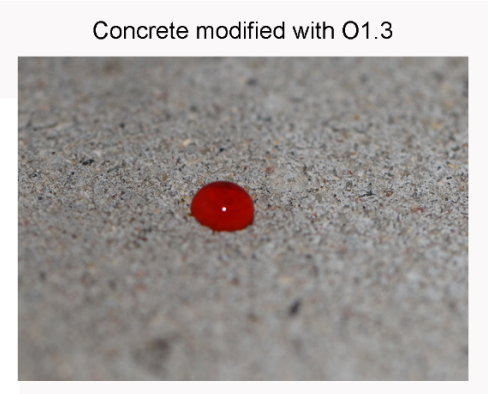

(b) water droplet directly after deposition

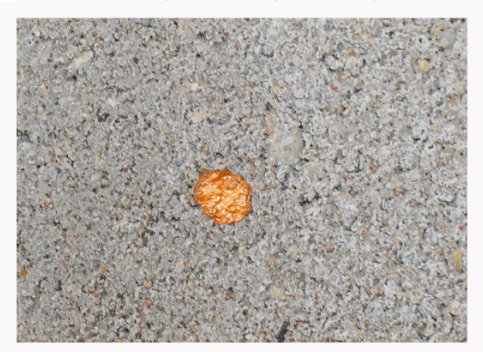

(d) water droplet after evaporation

FIGURE 5. Images of a water droplet dyed with methyl orange placed on the surface of unmodified $(\mathrm{a}, \mathrm{c})$ and modified by $\mathrm{O} 1.3$ concrete $(\mathrm{b}, \mathrm{d})$; directly after deposition and after evaporation. 


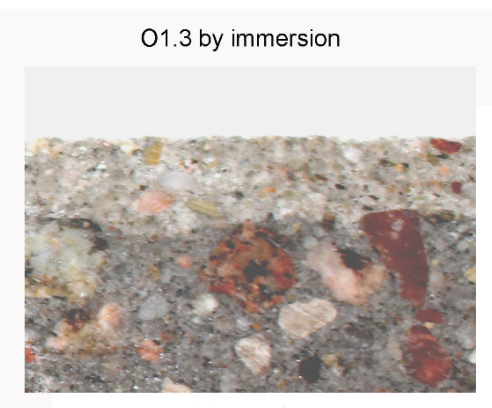

(a) raw photo

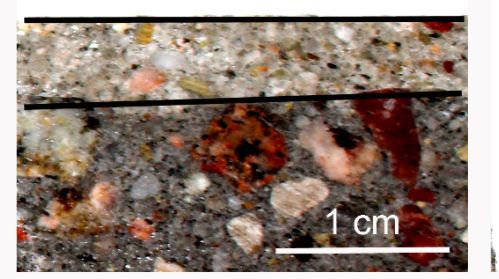

(c) after adjusting the contrast

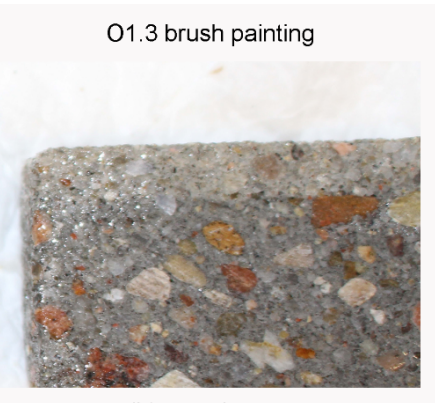

(b) raw photo

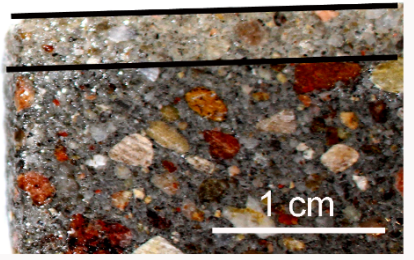

(d) after adjusting the contrast

FIGURE 6. Results of penetration depth revealing by water spraying on the cut concrete specimens.

and permits their use for a longer time. Further research is required to determine the durability of alcoholic OPTES solutions and coatings based on them. The results presented open new possibilities of using products of natural origin for the synthesis of organosilicon derivatives and their use for production of protective coatings stronger interacting with the surface of the material coated. Of course, the precise determination of the practical applicability of OPTES requires further research, especially aging tests.

\section{ACKNOWLEDGMENTS}

Author thanks Nuria Miguel from University of Zaragoza (in 2019/2020 as Erasmus Student working on her Bachelor Thesis at AMU) for Spanish translation. Author would like to express his gratitude to Center for Advanced Technologies in Poznan for giving us the opportunity to perform Scanning Electron Microscope images and Energy Dispersive Spectroscopy spectra. This work was supported by funds from the National Science Centre (Poland) granted on the basis of decision number DEC-2013/09/D/ST5/03845.

\section{REFERENCES}

1. Dhir, R.K.; Hewlett, P.C.; Chan, Y.N. (1987) Near-surface characteristics of concrete: assessment and development of in situ test methods. Mag. Concr. Res. 39, 183-195. https:// doi.org/10.1680/macr.1987.39.141.183.

2. Song, H-W.; Lee, C-H.; Ann, K.Y. (2008) Factors influencing chloride transport in concrete structures exposed to marine environments. Cem. Concr. Compos. 30, 113-121. https://doi.org/10.1016/j.cemconcomp.2007.09. 005 .
3. Meyer, A. (1987) Importance of the surface layer for the durability of concrete structures. ACI Spec. Publ. 100, 49-62.

4. Basheer, P.A.M.; Basheer, L.; Cleland, D.J.; Long, A.E. (1997) Surface treatments for concrete: assessment methods and reported performance. Constr. Build. Mater. 11 [7-8], 413-429. https://doi.org/10.1016/S0950-0618(97) 00019-6.

5. Doran, D.; Cather, B. (2013) Construction Materials Reference Book, Routledge, Taylor \& Francis Group, New York, (2013).

6. Pan, X.; Shi, Z.; Shi, C.; Ling, T-C.; Li, N. (2017) A review on concrete surface treatment Part I: Types and mechanisms. Constr. Build. Mater. 132, 578-590. https:// doi.org/10.1016/j.conbuildmat.2016.12.025.

7. Woo, R.S.C.; Zhu, H.; Chow, M.M.K.; Leung, C.K.Y.; Kim, J-K. (2008) Barrier performance of silane-clay nanocomposite coatings on concrete structure. Compos. Sci. Technol. 68 [14], 2828-2836. https://doi.org/10.1016/ j.compscitech.2007.10.028.

8. Anderson, R.; Arkles, B.; Larson, G.L. (1987) Silicon compounds register and review, Petrarch Product Catalog, Bristol, (1987).

9. Attanayaka, U.; Ng, S.Y.C.; Aktan, H. (2002) Criteria and benefits of penetrating sealants for concrete bridge decks, Michigan Department of Transportation, (2002).

10. A guide to silane solutions from Dow Corning, Dow Corning, (2005).

11. Petrie, E. (2007) Handbook of adhesives and sealants, McGraw Hill, New York, (2007).

12. Carter, P.D. (1994) Evaluation of dampproofing performance and effective penetration depth of silane sealers in concrete. ACI Spec. Publ. 151, 95-118.

13. Christodoulou, C.; Goodier, C.I.; Austin, S.A.; Webb, J.; Glass, G.K. (2013) Long-term performance of surface impregnation of reinforced concrete structures with silane. Constr. Build. Mater. 48, 708-716. https://doi.org/10.1016/ j.conbuildmat.2013.07.038.

14. Li, J., Yi, Z., Xie, Y. (2012) Progress of silane impregnating surface treatment technology of concrete structure. Mater. Rev. 26 [3], 120-125.

15. Pan, X.; Shi, Z.; Shi, C.; Ling, T-C.; Li, N. (2017) A review on surface treatment for concrete - Part 2: Performance. Constr. Build. Mater. 133, 81-90. https://doi.org/10.1016/ j.conbuildmat.2016.11.128. 
16. Dai, J-G., Akira, Y., Wittmann, F.H., Yokota, H., Zhang P. (2010) Water repellent surface impregnation for extension of service life of reinforced concrete structures in marine environments: The role of cracks. Cem. Concr. Comp. 32, 101-109. https://doi.org/10.1016/j.cemconcomp.2009.11. 001.

17. Zhan, H., Wittmann, F.H., Zhao, T. (2003). Chloride barrier for concrete in saline environment established by water repellent treatmentt. Restorat. Build. Monum. 9, 535-550. https://doi.org/10.1515/rbm-2003-5792 .

18. Wong, H.S.; Barakat, R.; Alhilali, A.; Saleh, M.; Cheeseman, C.R. (2015) Hydrophobic concrete using waste paper sludge ash. Cem. Concr. Res. 70, 9-20. https:// doi.org/10.1016/j.cemconres.2015.01.005.

19. Malinowski, R. (1977) Concretes and mortars in ancient aqueducts. In: Hist. Moments Concr. 1, 66-76.

20. Fiori, C. Vandini, M., Prati, S., Chiavari, G. (2009) Vaterite in the mortars of a mosaic in the Saint Peter Basilica, Vatican (Rome). J. Cult. Herit. 10, 248-257. https://doi.org/10.1016/j.culher.2008.07.011.

21. Lagazzo, A.; Vinci, S.; Cattaneo, C.; Botter, R. (2016) Effect of fatty acid soap on microstructure of lime-cement mortar. Constr. Build. Mater. 116, 384-390. https://doi.org/ 10.1016/j.conbuildmat.2016.04.122.

22. Nunes, C.; Slížková, Z. (2014) Hydrophobic lime based mortars with linseed oil: Characterization and durability assessment. Cem. Concr. Res. 61-62, 28-39. https://doi.org/ 10.1016/j.cemconres.2014.03.011.

23. Hewlett, P.C., Liska M. (2019) Lea's Chemistry of Cement and Concrete, Elsevier (2019)

24. Cellat, K.; Beyhan, B.; Güngör, C.; Konuklu, Y.; Karahan, O.; Dündar, C.; Paksoy, H. (2015) Thermal enhancement of concrete by adding bio-based fatty acids as phase change materials. Energy Build. 106, 156-163. https://doi.org/ 10.1016/j.enbuild.2015.05.035.

25. Rozanna, D.; Chuah, T.G.; Salmiah, A.; Choong, T.S.Y.; Sa'ari, M. (2005) Fatty acids as phase change materials
(PCMs) for thermal energy storage: a review. Int. J. Green Energy 1, 495-513. https://doi.org/10.1081/GE-200038722.

26. Justnes, H.; Østnor, T.A.; Barnils Vila, N. (2004) Vegetable oils as water repellents for mortars, In: Proceedings of the first international conference of Asian Concrete Federation, Chiang Mai, Thailand; 2, 689-98.

27. Szubert, K. (2018) Synthesis of organofunctional silane from rapeseed oil and its application as a coating material. Cellulose 25, 6269-6278. https://doi.org/10.1007/s1057 0-018-2018-6.

28. Szubert, K.; Maciejewski, H. (2017) Corrosion protective agent, PL424015 (A1) (2017).

29. EN-197-1, Cement - Part 1: Composition, specifications and conformity criteria for common cements, European Committee for Standardization, Brussels, (2011)

30. Orsavova, J.; Misurcova, L.; Ambrozova, J.V.; Vicha, R.; Mlcek, J. (2015) Fatty acids composition of vegetable oils and its contribution to dietary energy intake and dependence of cardiovascular mortality on dietary intake of fatty acids. Int. J. Mol. Sci. 16 , 12871-12890. https://doi.org/10.3390/ijms160612871.

31. EN-1062-3, Paints and varnishes. Coating materials and coating systems for exterior masonry and concrete Part 3: Determination of liquid water permeability, European Committee for Standardization, Brussels, (2008).

32. EN-1504-2, Products and systems for the protection and repair of concrete structures - Definitions, requirements, quality assurance and conformity assessment - Part 2: Surface protection systems for concrete, European Committee for Standardization, Brussels, (2004).

33. Baltazar, L.; Santana, J.; Lopes, B.; Rodrigues, M.P.; Correia, J.R. (2014) Surface skin protection of concrete with silicate-based impregnations: Influence of the substrate roughness and moisture. Constr. Build. Mater. 70, 191-200. https://doi.org/10.1016/j.conbuildmat. 2014.07.071. 